\title{
Co-Production of Aromatics in Biomass and Waste Gasification
}

\author{
Carlos Mourao Vilela*(D), Evert Boymans and Berend Vreugdenhil
}

Netherlands Organization for Applied Scientific Research (TNO), Energy Transition Unit, Westerduinweg 3, 1755 LE Petten, The Netherlands; evert.boymans@tno.nl (E.B.); berend.vreugdenhil@tno.nl (B.V.)

* Correspondence: carlos.mouraovilela@tno.nl; Tel.: +31-888-663-055

Citation: Mourao Vilela, C.; Boymans, E.; Vreugdenhil, B. Co-Production of Aromatics in Biomass and Waste Gasification. Processes 2021, 9, 463. https:// doi.org/10.3390/pr9030463

Academic Editor: Axel Funke

Received: 1 February 2021

Accepted: 27 February 2021

Published: 4 March 2021

Publisher's Note: MDPI stays neutral with regard to jurisdictional claims in published maps and institutional affiliations.

Copyright: (c) 2021 by the authors. Licensee MDPI, Basel, Switzerland. This article is an open access article distributed under the terms and conditions of the Creative Commons Attribution (CC BY) license (https:// creativecommons.org/licenses/by/ $4.0 /)$.

\begin{abstract}
Climate changes will have a huge impact on society, one that cannot be truly predicted. However, what is known is that our dependence on fossil feedstock for energy, fuel and chemical production will need to shift towards more biobased and circular feedstock. This paper describes part of an important technology development that uses biogenic and plastic-containing waste streams for the co-production of aromatics with fuels and/or chemicals. This paper captures the first decade of this technology development from idea towards a large Process Demonstration Unit operated and validated within a large gasification R\&D infrastructure. The scale-up was successful, with supporting tools to optimize and identify the limits of the technology. Benzene and toluene are directly removed from the product gas with $97 \%$ and $99 \%$ efficiency, respectively. The next steps will be to include this development in larger piloting and demonstrations for the co-production of aromatics from biomass gasification (biobased chemicals) or aromatics from plastic-containing waste gasification (circular chemicals).
\end{abstract}

Keywords: biomass gasification; waste gasification; bio-aromatics; BTX; SNG; circularity

\section{Introduction}

Climate changes have been well documented, and the past centuries have seen a few instances that were followed by catastrophic events. Around 535-536 AD (Anno Domini) there was a major climate anomaly that caused flooding and droughts on a global scale and off-set the natural course of things. What followed is known as the Justinian plague and this raged over Europe for 210 years, causing millions of people to die. Similar to this, the Black Plague around 1350 AD coincided with the beginning of the little ice age. The little ice age also resulted in dramatic climate effects, such as droughts, flooding, torrential rains, etc., which resulted in famine. This shows that changes in climate can have dramatic effects on how our society can function [1]. Besides climate playing an important role, it is argued that human behavior also plays an important role [2]. So, when climate is causing stress on our society, it will have consequences.

The IPCC (Intergovernmental Panel on Climate Change) is also connecting climate change to future scenarios that include war, famine and extreme weather events [3]. These are scenarios that are a consequence of a gradual increase in global temperatures, which is different to the two climate events mentioned before, where the temperature suddenly dropped several degrees, within a few years. Both climate eruptions have a high potential of resulting in global disruption.

This global disruption will affect the access to feedstock for the production of energy, fuels and chemicals, as a result causing stress in how countries relate to each other. Access to clean water and perhaps access to fertile or available land are also important parameters. In order to deal with changing environmental constraints, one must learn to become more versatile. It is in this light that the following work was done. By utilizing waste biogenic feedstocks or waste materials containing plastic as a new local and sustainable form of carbon, one can build value chains that rely more on what a country can produce versus what it can import. The petrochemical industry produces around 330 million tons of 
chemicals, primarily consisting of benzene, toluene, xylene (BTX), ethylene, propylene butadiene and methanol. All of these molecules, besides methanol, can be directly produced from the various carbonaceous feedstocks [4].

Within TNO (the Netherlands Organization for Applied Scientific Research) a value chain has been developed, depicted in Figure 1, that allows the highly efficient conversion of biogenic material into a substitute natural gas (SNG) [5]. The indirect gasification technology (the MILENA gasifier), which is key to this value chain, produces not only large quantities of methane, but also chemicals, such as benzene, toluene and ethylene. It was realized during the development of the SNG route that the business case could be improved by valorizing these chemicals, rather than converting them to methane. An improvement of $30 \%$ in the revenues is reported for a scenario with co-production of BTX (benzene, toluene and xylenes) and SNG [6] and an added value of 5 to $7 \%$ points on the return on investment is reported by co-production of BTX in waste-to-energy processes [7]. This article will show the versatility of the gasification technology to convert a broad spectrum of different feedstock into a medium calorific gas. It will also show how the development of the BTX removal technology (AREA) has been successfully scaled up from $1 \mathrm{Nm}^{3}$ dry gas to $5 \mathrm{Nm}^{3}$ dry gas, supported by process modelling. This work will also lead to new insights, in that, based on a certain feedstock, a specific value chain becomes less likely, but another value chain can be explored. This is particularly true when switching from biomass to plastic-containing waste streams.

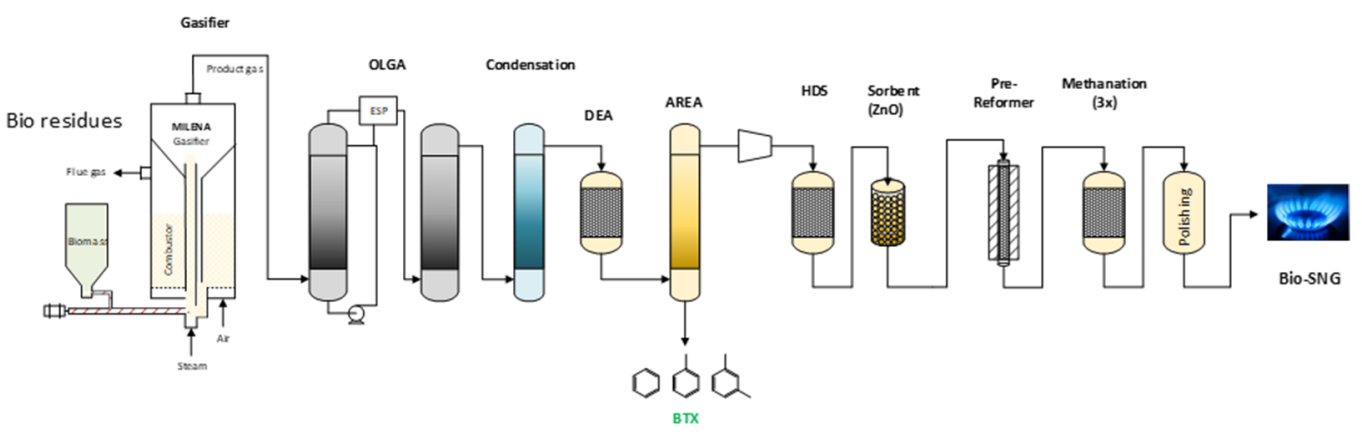

Figure 1. Bio-substitute natural gas (SNG) production route via biomass gasification developed at the Netherlands Organization for Applied Scientific Research (TNO).

The SNG production route from biomass gasification is a highly efficient ( $70 \%$ on energy basis) value chain towards methane, since the gasifier provides a large amount of methane. When shifting towards plastic-containing wastes (RDF or paper rejects) the concentration of chemicals (benzene, toluene and ethylene) increases, which makes a route towards SNG less likely/feasible. The removal of benzene and toluene (co-production) provides economic and technical benefits for the lineup, as has been shown elsewhere $[6,7]$. Bio-aromatics are valuable components as they serve as chemical building blocks towards more renewable materials instead of depending on fossil sources, especially since gasification can be applied to process municipal solid waste as well, which means that rather going to incineration or landfilling, these waste materials can be used to produce chemicals, fuels and energy.

The required AREA technology has been developed in parallel to the bio-SNG/fuels route. It allows extraction of the aromatics, mainly benzene and toluene, formed in the gasification reactor. The carbon yield towards aromatics that can be obtained for woody biomass gasification in MILENA are about $15 \mathrm{wt} \%$, which includes tar. About $5 \mathrm{wt} \%$ of this is benzene. In the SNG lineup, as described and shown in Figure 1, the heavier aromatics (bigger than toluene) are selectively extracted from the gas in the OLGA tar scrubber. The lighter aromatics, predominantly benzene and toluene, are left in the product gas and can be removed using AREA. 
Other competing processes, with raw biomass as feedstock, include biomass pyrolysis and sugar-refining routes [8]. Lab-scale in situ and ex situ catalytic pyrolysis of biomass has shown potential BTX yields of 10-20\% [9]. Commercially, Anellotech in the USA and BioBTX in the Netherlands are developing technology for the production of BTX, based on catalytic fast pyrolysis [10]. Alternatively, isolated sugars and lignin can be refined to aromatics via chemical conversion; for instance, the conversion of C5/C6 sugars into furanics, followed by Diels-Alder chemistry to aromatics [11]. Disadvantages of the latter are that many chemical conversion steps are required and the final yields of mostly specialty aromatics are low.

The approach presented here differentiates from those above, since with gasification the aim is not to solely produce BTX, which is a valuable by-product.

The work reported here includes the developments and results on the aromatics extraction unit (AREA). Results obtained from multiple projects are included to illustrate the versatility of the technology and the quality of the liquid BTX product will be reported and discussed. Part of the development is the up-scaling of the unit from $1 \mathrm{Nm}^{3} / \mathrm{h}$ dry gas input (pre 2020) to a $5 \mathrm{Nm}^{3} / \mathrm{h}$ installation (post 2020), with supporting modelling tools.

\section{Materials and Methods}

\subsection{Feedstock}

In this experimental work, several different feedstocks were used, ranging from lignocellulosic material to plastic waste. Table 1 provides the general composition of the tested samples, as analyzed at TNO.

Table 1. Feedstock composition analyzed at the TNO facilities ( $w \mathrm{t} \%$ on dry basis).

\begin{tabular}{ccccccccc}
\hline Feedstock & $\mathbf{C}$ & $\mathbf{H}$ & $\mathbf{O}$ & $\mathbf{N}$ & $\mathbf{S}$ & $\mathbf{C l}$ & Volatile Matter & Ash \\
\hline Beechwood & 47.4 & 6.4 & 48.7 & 0.2 & $<0.1$ & $<0.1$ & 80.9 & 1.3 \\
Lignin & 47.2 & 5.6 & 33.0 & 1.3 & 0.2 & $<0.1$ & 65.0 & 14.0 \\
Sewage sludge & 30.1 & 4.4 & 27.3 & 4.2 & 1.3 & $<0.1$ & 62.7 & 73.1 \\
Paper rejects & 50.1 & 6.9 & 30.4 & 0.3 & 0.1 & 0.8 & 1.0 & 11.2 \\
RDF $^{1}$ & 44.7 & 6.6 & 26.4 & 0.4 & 0.2 & 1.0 & 66.4 & 21.9 \\
Plastic waste & 61.0 & 9.5 & 13.0 & 0.9 & 0.2 & 0.4 & 80.6 & 18.6 \\
\hline
\end{tabular}

${ }^{1}$ Refuse-derived fuel.

With the exception of beechwood, which was used as received (Rettenmeier chips, 2-4 mm), all the other feedstocks had to be pre-processed prior the gasification tests. Lignin and sewage sludge were dried for $48 \mathrm{~h}$ and then milled. Paper rejects were first pelletized and then milled. RDF, received as pellets, were milled. The plastic waste was first shredded, then pelletized, and then milled. In all cases, the milling process was performed with a Retch SM300 equipped with a screen of $6 \mathrm{~mm}$. All the materials had to be ground to a size smaller than $6 \mathrm{~mm}$ due to restrictions imposed by the feeding entrance at the MILENA gasifier. More details on the pre-processing can be found elsewhere [12-15].

\subsection{Experimental Setup}

The diagram of the experimental lineup used in this work is shown in Figure 2. Biomass was gasified in the lab scale $25 \mathrm{~kW}_{\text {th }}$ MILENA reactor generating the product gas. The MILENA technology, the first unit in Figure 2, applies indirect gasification where the gasification reactions are separated from the combustion section, which is used to provide the necessary heat for the all process. It consists of a riser, where the fast devolatilization/gasification of the biomass takes place, and a bubbling fluidized bed combustor, where the remaining char is burned. The solids (char and bed material) are separated in the settling chamber from the product gas and recirculated to the combustor through the downcomer. The internal circulation of bed material between the combustor and the riser will ensure the heat transport. The lab-scale reactor is provided with heat tracing to compensate for heat losses. The main advantage of this system is that it allows the operation to occur 
without the use of oxygen (or air) in the gasification process, resulting in a product gas low in $\mathrm{N}_{2}$. The MILENA technology is comprehensively detailed elsewhere [16]. A slipstream of about $1 \mathrm{Nm}^{3} / \mathrm{h}$ dry gas (about $20 \%$ of the total product gas generated) was sent to the downstream processing, while the rest was sent to an afterburner. This slipstream first passed through a hot-gas filter (sintered metal filter) set at $400-450{ }^{\circ} \mathrm{C}$ for the removal of dust. Subsequently, the dust-free product gas was led through the tar scrubber columns that lowers the tar concentration to a dew point of approximately $10^{\circ} \mathrm{C}$. More details on the tar removal can be found elsewhere [17]. Subsequently, benzene and other light aromatics were extracted in the BTX absorber unit (AREA). The tar and BTX-free product gas can be upgraded into biofuels via additional gas cleaning and catalytic conversion; however, this is not part of the work described here.

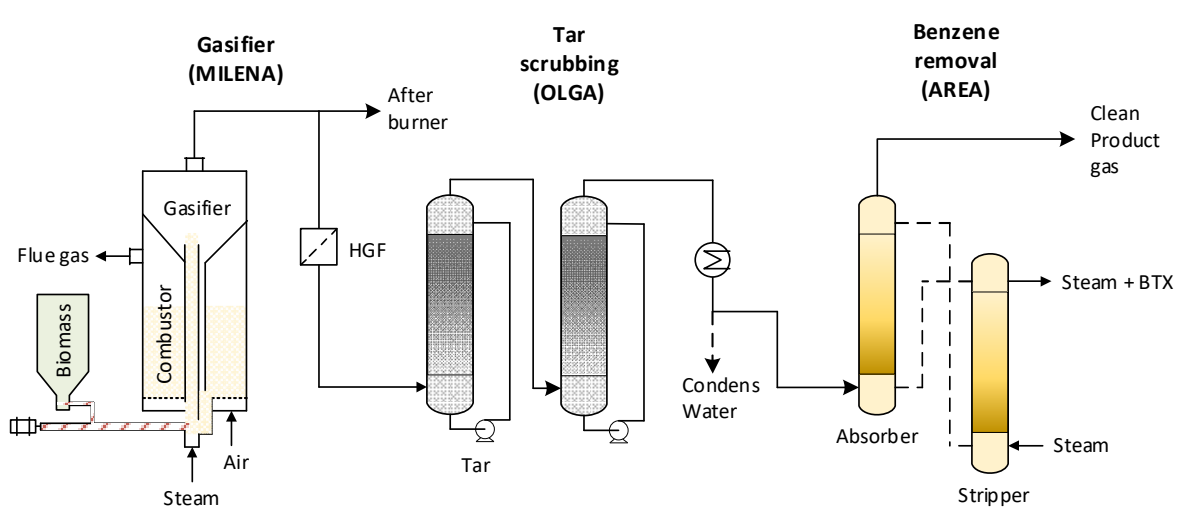

Figure 2. Process flow diagram of the experimental setup.

\subsubsection{Gasifier Settings}

The several feedstocks presented in Table 1 were gasified in the MILENA reactor at a typical $5 \mathrm{~kg} / \mathrm{h}$ and with steam-nitrogen as the carrier gas. The bed material used was either sand $(0.1-0.5 \mathrm{~mm})$ or olivine $(0.1-0.4 \mathrm{~mm})$. Table 2 shows the average parameters applied in the Milena reactor.

Table 2. Average settings of the MILENA gasifier.

\begin{tabular}{ccc}
\hline Parameter & & \\
\hline Feedstock flow & $\mathrm{kg} / \mathrm{h}$ & $3-5$ \\
Bed material & $(-)$ & Sand or Olivine \\
Bed material & $\mathrm{kg}$ & 40 \\
Temperature & ${ }^{\circ}$ & $730-850$ \\
Carrier gas & $(-)$ & Steam- $\mathrm{N}_{2}$ \\
Steam to carbon & $\mathrm{kg} / \mathrm{kg}$ & $0.4-0.6$ \\
Air to combustor & $\mathrm{Nm}^{3} / \mathrm{h}$ & 6 \\
\hline
\end{tabular}

\subsubsection{OLGA Tar Scrubber Settings}

For the selective removal of tar, the so-called OLGA technology was applied, which is designed to operate above the water dew point and for minimal removal of benzene and toluene. A schematic representation of OLGA is shown in Figure 3. OLGA consists of two cleaning units with separate scrubbing fluids. In the first unit, the product gas first passes through the collector where the heaviest tars are collected followed by an additional reactor (VIVA column) for the removal of aerosols. The second unit consists of an absorberstripper combination, where the absorber removes light tars, and the oil is regenerated in the stripper using $\mathrm{N}_{2}$ as the stripping medium. A slipstream of approximately $1 \mathrm{Nm}^{3} / \mathrm{h}$ producer gas from MILENA was directed to OLGA and the downstream system. The slipstream first passes through a hot gas filter, which was set at $400{ }^{\circ} \mathrm{C}$. Then the gas is cooled to $80^{\circ} \mathrm{C}$ in the first OLGA unit followed by an absorption step in the second unit 
at $80^{\circ} \mathrm{C}$. Water was condensed separately downstream at a temperature of $10^{\circ} \mathrm{C}$. More details on the tar removal can be found elsewhere [17].

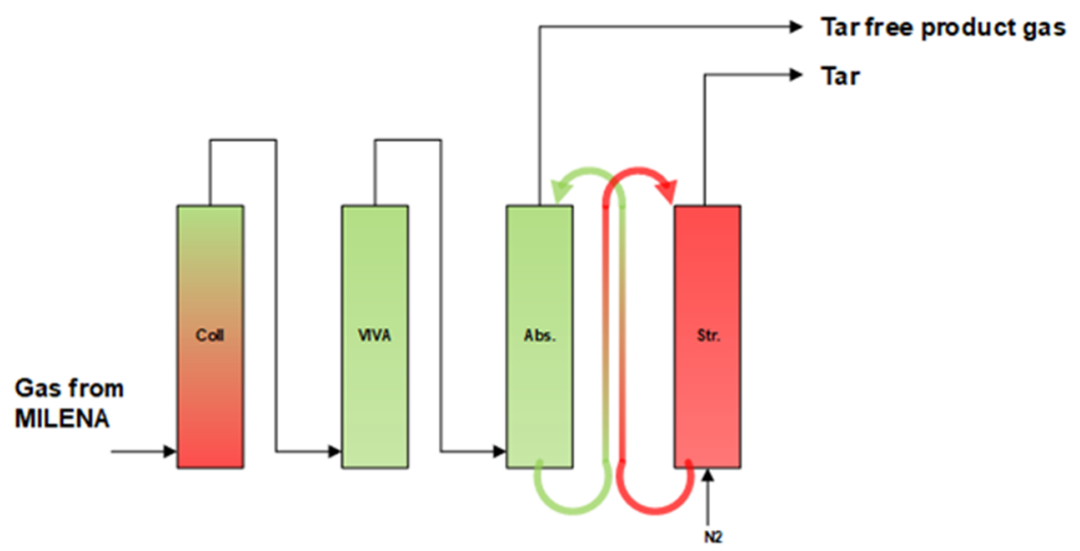

Figure 3. Scheme of the OLGA tar removal system.

\subsubsection{AREA Settings}

AREA (Aromatics REcovery Apparatus) is a unit dedicated to the selective removal of BTX components from the tar-free product gas developed at TNO. The typical settings can be found in Table 3.

Table 3. Typical settings of the Aromatics REcovery Apparatus (AREA).

\begin{tabular}{ccc}
\hline Parameter & & \\
\hline Product gas inlet & $\mathrm{Nm}^{3} / \mathrm{h}$ & 1 \\
Temperature absorber & ${ }^{\circ} \mathrm{C}$ & 35 \\
Temperature stripper & ${ }^{\circ} \mathrm{C}$ & 160 \\
Oil circulation rate & $\mathrm{kg} / \mathrm{h}$ & 30 \\
Stripper steam & $\mathrm{kg} / \mathrm{h}$ & 0.8 \\
Column height absorber & $\mathrm{m}$ & 2 \\
Column height stripper & $\mathrm{m}$ & 2 \\
\hline
\end{tabular}

\subsection{Gas Analysis}

The online ABB Advanced Optima analyzer system is placed after the MILENA, providing continuous monitoring of the gas composition:

- $\quad$ NDIRs (non-dispersive infrared detectors) for $\mathrm{CO}, \mathrm{CO}_{2}$ and $\mathrm{CH}_{4}$;

- TCD detector for $\mathrm{H}_{2}$ measurement;

- paramagnetic detector for $\mathrm{O}_{2}$ measurement.

The online Varian CP4900 4-channel micro-GCs are placed after the MILENA, OLGA and AREA, providing continuous monitoring (every $4-5 \mathrm{~min}$ ) of the gas composition:

- Molsieve 5A 10 m; channel for $\mathrm{H}_{2}, \mathrm{O}_{2} / \mathrm{Ar}, \mathrm{N}_{2}, \mathrm{CH}_{4}$ and CO;

- Poraplot U $10 \mathrm{~m}$; channel for $\mathrm{CO}_{2}, \mathrm{C}_{2} \mathrm{H}_{4}, \mathrm{C}_{2} \mathrm{H}_{6}$ and $\mathrm{C}_{2} \mathrm{H}_{2}$;

- Poraplot U $10 \mathrm{~m}$; channel for $\mathrm{H}_{2} \mathrm{~S}$ and COS;

- $\quad$ special module; channel for benzene and toluene.

\subsection{Liquid Analysis}

GC-MS-FID analysis was used of the aromatics (tar). An Agilent 7890A GC coupled to a mass detector (triple-axis MSD 5975C) was used for the identification of tar compounds and a Thermo Scientific Trace 1310 GC with flame ionization detector (FID) for the quantification of the tar compounds. The GC is calibrated with certified PAH-mix standards. Response factors are used for adjoining unidentified peaks ("unknown tars"). 


\section{Results}

\subsection{Benzene and Toluene in MILENA Product Gas}

Benzene and toluene are directly extracted from the product gas using the AREA technology; however, their yields are determined firstly by how much is formed in the gasifier. Therefore, the effect of the conditions and feedstock on the benzene and toluene concentrations when applying the MILENA gasifier will be addressed first.

The benzene and toluene concentrations obtained from several experimental campaigns with beechwood as feedstock are shown in Figure 4 as a function of temperature. As can be observed, at higher temperature, especially the concentration of benzene seems to increase gradually, whereas that of toluene decreases. Furthermore, sand as bed material provides a higher benzene concentration and a similar toluene concentration. Olivine is often applied as the bed material as it reduces the overall tar concentration in the product gas; however, it also leads to a reduction in benzene concentration.

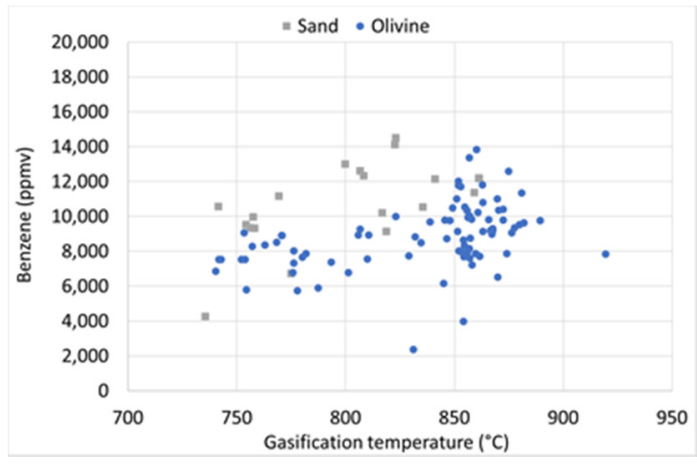

(a)

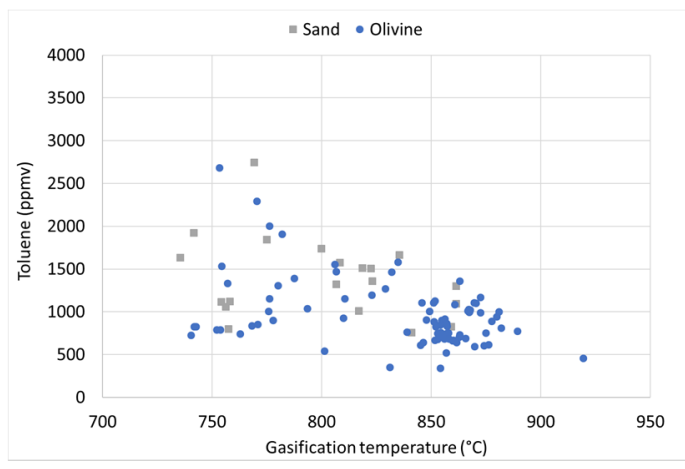

(b)

Figure 4. Concentrations in the product gas from atmospheric steam gasification in MILENA using sand and olivine: (a) benzene; (b) toluene.

Several other feedstocks have been applied in the gasification process with the MILENA reactor, which have resulted in different gas compositions.

The results for beechwood, lignin, sewage sludge, paper rejects, RDF and plastic waste are listed in Table 4 . These results show the versatility of the process as they represent waste streams from biorefinery processes, municipal waste and plastic recycling. $\mathrm{Ne}$ is introduced in the reactor at a fixed flow as the internal standard, and since its concentration is measured with the micro-GC, it allows the calculation of the total flow of product gas. It should be stressed that, as the gasifier is designed for woody biomass, alternative feedstock gasification involved dilution with $\mathrm{N}_{2}$ at varied amounts, depending on the other gasification parameters. For this reason, the carbon yield $(\mathrm{C} \%)$ that represents the fraction of carbon from the original feedstock that ends up as benzene and toluene is also shown.

It is important to stress that each one of these tests was part of a different project and with different goals. For example, some of these tests required olivine as bed material to minimize the tar formation while others required an inert bed material. It will not be the purpose here to explain the gasification mechanism and the influence of each parameter, but rather to acknowledge that the gasification parameters, including the feedstock, have an influence in the product gas composition. However, there are some evidence on the effect of the feedstock on the product gas composition that should be highlighted, especially with respect to benzene and toluene. Beechwood and lignin generate the largest amounts of $\mathrm{CO}$ and $\mathrm{CO}_{2}$ while the plastic waste generates the least amount. This seems to be correlated to the amount of oxygen in the composition of the feedstock that will then end up mostly in the form of $\mathrm{CO}$ and $\mathrm{CO}_{2}$ upon the gasification. Beechwood contains almost $49 \%$ oxygen while the plastic waste contains about $13 \%$ oxygen. On the other side the streams richer in plastic generate more lower hydrocarbons, such as $\mathrm{CH}_{4}$ and $\mathrm{C}_{2} \mathrm{H}_{4}$, and more benzene and toluene. 
Table 4. Averaged product gas composition from the different feedstocks on a dry and tar-free basis.

\begin{tabular}{|c|c|c|c|c|c|c|c|}
\hline & Beechwood & Beechwood & Lignin & Sewage Sludge & Paper Rejects & RDF & Plastic Waste \\
\hline Temperature $\left({ }^{\circ} \mathrm{C}\right)$ & 820 & 820 & 780 & 800 & 800 & 760 & 730 \\
\hline Bed material & sand & olivine & olivine & sand & olivine & olivine & sand \\
\hline $\mathrm{H}_{2}(\mathrm{Vol} \%)$ & 18.1 & 23.5 & 8.6 & 6.9 & 7.0 & 6.4 & 7.9 \\
\hline $\mathrm{CO}(\mathrm{Vol} \%)$ & 35.4 & 36.5 & 13.9 & 7.2 & 8.1 & 8.4 & 2.9 \\
\hline $\mathrm{CO}_{2}(\mathrm{Vol} \%)$ & 18.5 & 17.4 & 17.9 & 10.7 & 6.2 & 13.0 & 3.8 \\
\hline $\mathrm{CH}_{4}(\mathrm{Vol} \%)$ & 17.1 & 12.3 & 5.9 & 3.3 & 7.1 & 7.2 & 15.4 \\
\hline $\mathrm{C}_{2} \mathrm{H}_{4}(\mathrm{Vol} \%)$ & 5.6 & 4.2 & 2.8 & 2.0 & 5.3 & 6.1 & 15.5 \\
\hline $\mathrm{N}_{2}(\mathrm{Vol} \%)$ & 1.6 & 4.5 & 45.1 & 63.9 & 62.1 & 51.9 & 47.0 \\
\hline $\mathrm{C}_{6} \mathrm{H}_{6}(\mathrm{ppmV})$ & 11,400 & 8000 & 5000 & 2800 & 9200 & 8500 & 18,800 \\
\hline $\mathrm{C}_{7} \mathrm{H}_{8}(\mathrm{ppmV})$ & 1400 & 1100 & 1000 & 1000 & 1000 & 1500 & 2500 \\
\hline $\mathrm{C}_{6} \mathrm{H}_{6}(\mathrm{C} \%)$ & 5.3 & 3.7 & 3.2 & 3.0 & 8.6 & 6.9 & 8.8 \\
\hline $\mathrm{C}_{7} \mathrm{H}_{8}(\mathrm{C} \%)$ & 1.0 & 0.6 & 1.2 & 1.2 & 1.1 & 1.4 & 1.4 \\
\hline
\end{tabular}

The effect of olivine on the yield of benzene and toluene is clearly seen in the gasification of beechwood. At $820^{\circ} \mathrm{C}$ and in the presence of sand, 11,400 ppmV benzene (5.3 C\%) and $1400 \mathrm{ppmV}$ toluene $(1.0 \mathrm{C} \%)$ can be found in the product gas, whereas with olivine these values drop to $8000 \mathrm{ppmV}$ and $1100 \mathrm{ppmV}$, respectively.

For RDF, even at a somewhat lower temperature, already a higher carbon yield of respectively 6.9 and $1.4 \%$ was achieved. For plastic waste, the highest carbon yield with $8.8 \%$ benzene was found. This can be explained by the high plastic content, which results in a high concentration of light olefins and consequently aromatics under gasification conditions.

It is seen that the feedstock has a clear influence in the product gas composition. How this affects the aromatics extraction from the product gas and the BTX sample quality will be addressed in the following subsection.

\subsection{AREA Development}

It has been recognized that the presence of aromatics, such as benzene and toluene, in the product gas represent potential value. Besides, for the production of fuels, such as in the bio-SNG route, the presence of aromatics increases the coke formation over downstream catalytic beds or fouling in pumps due to their low intrinsic vapor pressure. Hereby, the removal of aromatics from the product gas may increase the revenues and at the same time simplify the process.

The removal of benzene and toluene through condensation out of the complex product gas was ruled out as a viable option, since extremely low temperatures would be needed. For example, the saturation vapor pressure of benzene at a concentration of $1.2 \mathrm{vol} \%$ is $-18{ }^{\circ} \mathrm{C}$; i.e., a $90 \%$ removal would require a temperature of $-50{ }^{\circ} \mathrm{C}$. For this reason, an absorption process was selected, with an absorption liquid/oil that is in contact with the product gas in an absorber column. The aromatic-free product gas leaves the absorber column and the oil is pumped to a separate stripper column in which the BTX is stripped from the oil at a high temperature using steam. The stripped BTX together with steam enter the cooling system where the full stream condenses. This installation for the removal of BTX from the product gas is known as the Aromatics REmoval Apparatus (AREA).

The properties of the oil were carefully selected for the efficient removal of BTX, including a low vapor pressure (avoiding loss in the stripper) and naturally a high affinity for aromatics. This is described elsewhere [18].

AREA-1, shown in Figure 5, was first developed and operated at atmospheric pressure, with an inlet gas flow rate of about $1.0 \mathrm{Nm}^{3} / \mathrm{h}$ dry gas, an absorber temperature of $35^{\circ} \mathrm{C}$, a stripper temperature of $160{ }^{\circ} \mathrm{C}, 0.8 \mathrm{~kg} / \mathrm{h}$ of steam and an oil (absorbent) circulation rate of $30 \mathrm{~kg} / \mathrm{h}$. These installation temperature and flow settings were applied based on results of early developments and designed to maximize the harvest of BTX from the product gas [19]. 


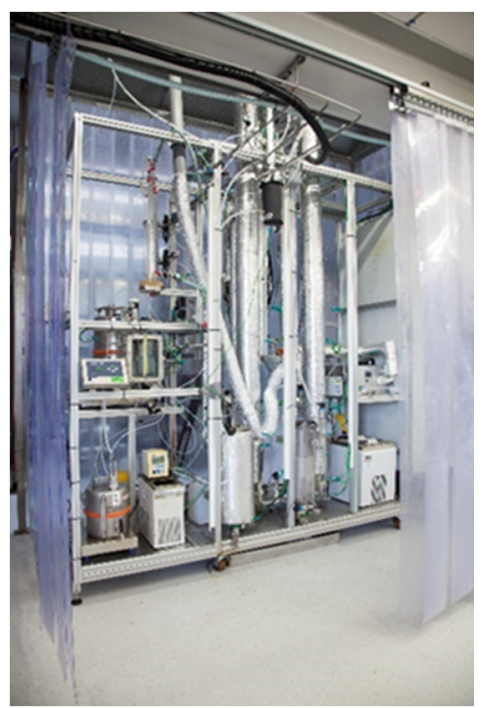

(a)

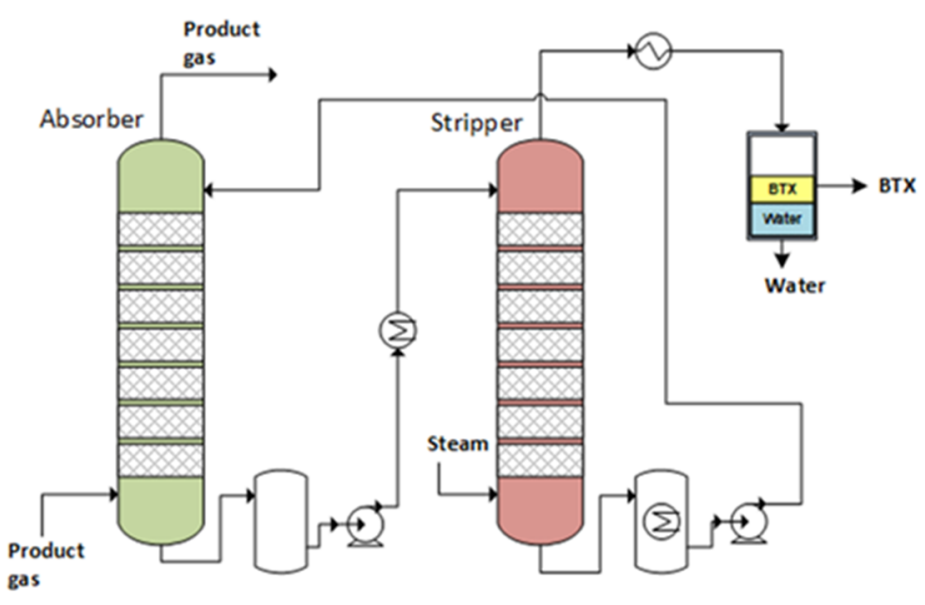

(b)

Figure 5. AREA-1 before scale-up: (a) AREA-1 at TNO; (b) process flow diagram of AREA-1.

The stripper gas containing the steam and BTX is allowed to condense after which phase separation between the BTX and water occurs, as shown in Figure 6. This automated process has been comprehensively detailed elsewhere [19]. The regenerated oil is cooled to the absorber temperature and sent back to the absorber. The operating pressure during the whole process is atmospheric.

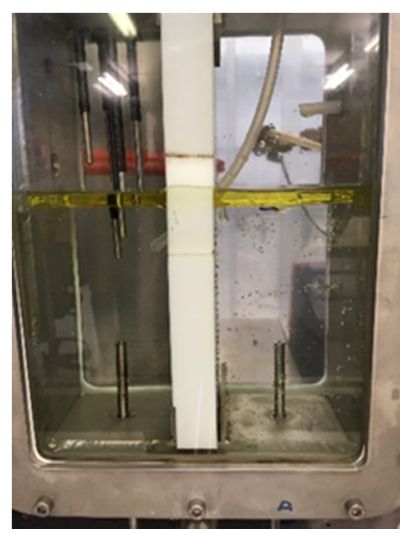

(a)

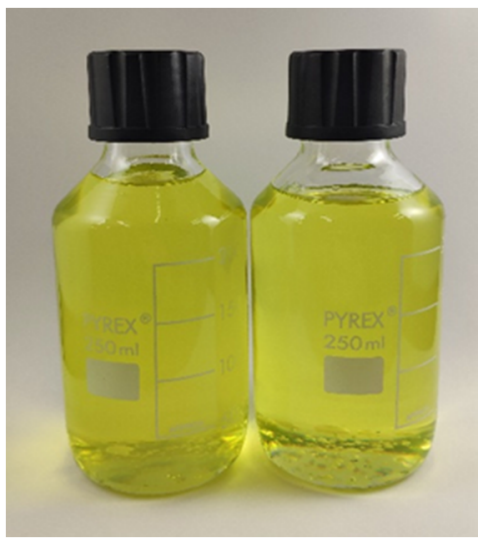

(b)

Figure 6. (a) The automated BTX and water phase separation system; (b) BTX final product.

The performance of AREA was assessed by monitoring online with micro-GCs the benzene and toluene that entered and left the unit. AREA was designed to remove benzene and toluene from the product gas with high efficiency and at different input gas compositions. As shown in the previous section, the input product gas composition will be dependent on the parameters applied in the MILENA-OLGA technologies as well as on the type of feedstock. Over the years, AREA-1 has been applied and developed in different projects, with different feedstocks and therefore at varying inlet gas compositions. Table 5 shows the average removal efficiency with different types of feedstock gasification. 
Table 5. The benzene and toluene removal efficiency from the product gas (PG) in the AREA at different gasification processes.

\begin{tabular}{ccccc}
\hline Feedstock & $\begin{array}{c}\text { Benzene PG } \\
\text { ppmV db }\end{array}$ & $\begin{array}{c}\text { Benzene Removal } \\
\text { Efficiency (\%) }\end{array}$ & $\begin{array}{c}\text { Toluene PG } \\
\text { Vol\% db }\end{array}$ & $\begin{array}{c}\text { Toluene Removal } \\
\text { Efficiency (\%) }\end{array}$ \\
\hline Beechwood & 8000 & 98.8 & 1000 & $>99$ \\
Lignin & 5600 & 98.2 & 1700 & $>99$ \\
Sewage sludge & 2800 & 98.6 & 1000 & $>99$ \\
Paper rejects & 9200 & 97.8 & 1000 & $>99$ \\
RDF & 8500 & 98.3 & 1500 & $>99$ \\
Plastic waste & 18,800 & 98.5 & 2500 & $>99$ \\
\hline
\end{tabular}

${ }^{7}$ Dry basis.

It can be seen that regardless of the composition of benzene and toluene in the product gas they are selectively removed with efficiencies $>97 \%$ for benzene and $>99 \%$ for toluene. However, there are other aromatics still present in the product gas that are removed together with the benzene and toluene. Hereby, these components will be collected and harvested with the final BTX product. As such, the harvested BTX has several differences, which are dependent on the parameters and feedstock applied in the gasification. Table 6 shows the composition of the collected BTX samples.

Table 6. Characterization of the collected BTX samples (wt\%).

\begin{tabular}{cccccc}
\hline Feedstock & Benzene & Toluene & $\begin{array}{c}\text { Xylenes and } \\
\text { Styrene }\end{array}$ & Ethylbenzene & Others \\
\hline Beechwood & 86 & 9 & 2 & 0 & 3 \\
Lignin & 69 & 24 & 3 & 2 & 2 \\
Sewage sludge & 61 & 20 & 8 & 1 & 10 \\
Paper rejects & 74 & 11 & 8 & 1 & 9 \\
RDF & 59 & 15 & 2 & 1 & 20 \\
Plastic waste & 64 & 13 & 5 & 17 \\
\hline
\end{tabular}

It can be seen that there are large differences in the composition of the collected BTX samples, though for all cases benzene followed by toluene are the main components. It seems that a larger fraction of plastic in the feedstock will lead to a larger variation of molecules being collected given the high number of "others". Though not part of this study, it should be stated that the composition of the harvested BTX is important for its market implementation and will have an influence on the type of treatment that may be needed.

\subsection{Optimization and Scale-Up}

For optimization/process intensification of the AREA-1 installation, two sets of experiments were carried out over two days to assess its performance. RDF gasification provided the PG needed (see also Table 4), from which gas was sent to AREA for removal of the aromatics. The AREA absorption capacity performance was monitored on the basis of the benzene concentration in the PG only, which was measured by $\mu-G C$ at the inlet of the AREA absorber and the outlet of the AREA absorber. Several parameters of the absorber-stripper combination were varied, such as the oil circulation rate (L) and the stripper steam, while all the other parameters remained constant, as listed in Table 3. An overview of the obtained results during the two days tests can be found in Table 7. 
Table 7. Summary of the AREA-1 benzene removal efficiency results. The removal efficiency is based on an average inlet concentration of 8850 ppmV benzene.

\begin{tabular}{|c|c|c|c|c|c|}
\hline Day & $\begin{array}{l}\text { Oil Circulation } \\
\text { Rate, L kg/h }\end{array}$ & $\begin{array}{l}\mathrm{L} / \mathrm{G}^{8}{ }_{\text {abs }} \\
\mathrm{Kg} / \mathrm{Nm}^{3}\end{array}$ & Steam $\mathrm{kg} / \mathrm{h}$ & $\begin{array}{c}\text { Benzene Outlet } \\
\text { ppmV }\end{array}$ & $\begin{array}{c}\text { Removal } \\
\text { Efficiency\% }\end{array}$ \\
\hline 1.1 & 30 & 33 & 0.80 & 300 & 96.5 \\
\hline 1.2 & 20 & 22 & 0.80 & 240 & 97.3 \\
\hline 1.3 & 10 & 11 & 0.80 & 260 & 97.1 \\
\hline 1.4 & 6 & 7 & 0.80 & 590 & 93.3 \\
\hline 1.5 & 5 & 6 & 0.80 & 840 & 90.6 \\
\hline 2.1 & 30 & 33 & 0.80 & 270 & 97.0 \\
\hline 2.2 & 30 & 33 & 0.40 & 220 & 97.5 \\
\hline 2.3 & 30 & 33 & 0.08 & 1070 & 87.9 \\
\hline 2.4 & 10 & 11 & 0.26 & 380 & 95.7 \\
\hline
\end{tabular}

${ }^{8} \mathrm{G}$ corresponds to the inlet product gas as $\mathrm{Nm}^{3} / \mathrm{h}$.

As can be observed during Day 1, only when the liquid flow rate was lowered to $6 \mathrm{~kg} / \mathrm{h}(\mathrm{L} / \mathrm{G}=7)$ did the removal efficiency start to decrease from $97+\%$ to $93 \%$. From this it can be concluded that the installation could run with three times less oil $(10 \mathrm{~kg} / \mathrm{h}$ instead of $30 \mathrm{~kg} / \mathrm{h}$ ), without a loss in benzene removal efficiency.

During Day 2, the flow rate of the stripping gas (steam) was varied. It can be observed that only when lowering the stripper steam from 0.4 to $0.08 \mathrm{~kg}$ a decrease in removal efficiency occurs from $97+\%$ to $88 \%$. A lower steam stripping means that more BTX, dissolved in the oil, flows back to the absorber. This results in a less efficient benzene removal from the gas. Furthermore, at $0.08 \mathrm{~kg} / \mathrm{h}$ of steam, the benzene outlet concentration (not shown) is not stable; it keeps on increasing.

This collection of empirical data was used to set up a process model for benzene as the model component. This model can predict, based on the inlet gas flow and the concentration of benzene, what amount of benzene will be removed at a certain column height. This became crucial in upgrading and scaling-up the process development unit AREA-1.

The developed model is based on a mass-transfer-rate equation and the Colburn equation $[20,21]$. In this equation, the number of transfer units and thereby the length of the column can be determined based on the desired removal of a gas component (here benzene). $N T U$ is the number of transfer units, $m$ is the equilibrium constant, $L_{m}$ is the molar liquid flow, $G_{m}$ is the molar gas flow, $y_{1}$ and $y_{2}$ are respectively the component gas concentration and $x_{1}$ and $x_{2}$ are respectively the in- and outgoing component liquid concentration.

$$
N T U=\frac{1}{1-\left(m \frac{G_{M}}{L_{M}}\right)} \ln \left[\left(1-\frac{m G_{M}}{L_{M}}\right)\left(\frac{y_{1}-m x_{2}}{y_{2}-m x_{2}}\right)+\frac{m G_{M}}{L_{M}}\right]
$$

The NTU is specific for the type of packing, as the height of a transfer unit times the actual height of the column. By defining the ingoing gas component's concentration, the outgoing gas concentration can be calculated. This equation was fit to the experimental data, as shown in Figure 7. 


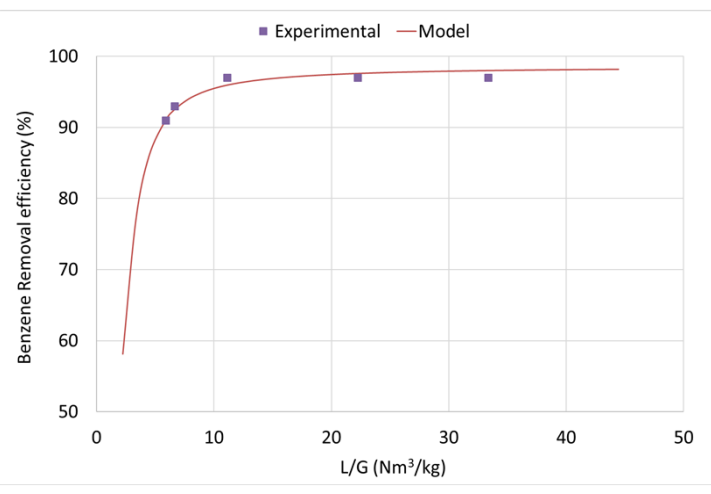

(a)

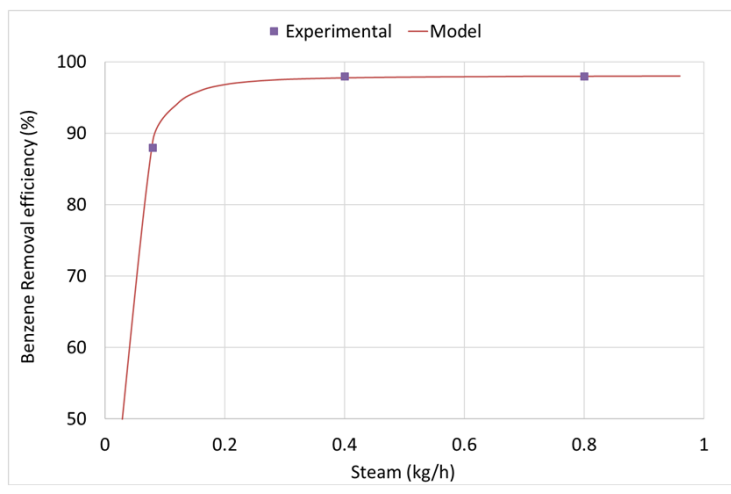

(b)

Figure 7. Experimental data of the benzene removal versus model calculations with (a) oil circulation and (b) steam.

\subsection{Upscaling to AREA-5}

In the year 2020, AREA was upscaled to be able to process the full product gas generated in the MILENA gasifier. In past work, a slip-stream of about $1 \mathrm{Nm}^{3} / \mathrm{h}$ of the MILENA gasifier was used and this was upgraded to the full gasifier capacity of $3-5 \mathrm{Nm}^{3} / \mathrm{h}$ product gas in AREA-5. Hereby, much larger quantities of BTX can be collected during the running process. Several instrument/mechanical improvements have been realized in the scale-up to AREA- 5 based on the lessons learned from AREA-1. One of the changes that was realized, due to the increased scale, was the plate-type heat exchangers that were installed for the oil circulation, to allow heat recovery between the hot and cold stream. Figure 8 shows the upscaled AREA-5.

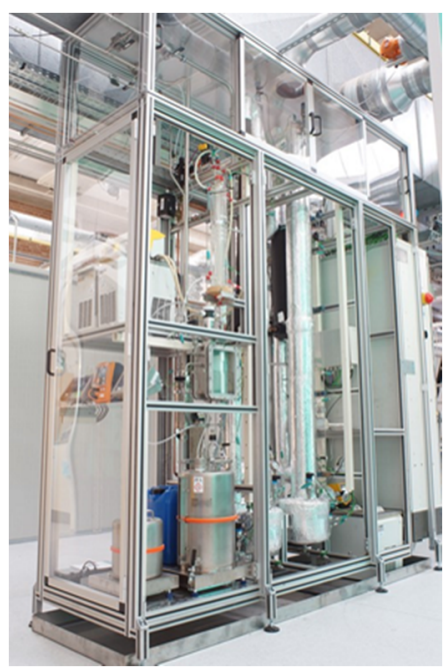

Figure 8. Bio-upscaled AREA-5 at TNO.

The experimental data and the modelling work performed with AREA-1 showed that the BTX extraction process could be optimized. It was found that:

- The oil circulation rate, and thereby the $\mathrm{L} / \mathrm{G}$, could be lowered substantially in the absorber with similar BTX capture. The $\mathrm{L} / \mathrm{G}$ ratio could be lowered from $\sim 33 \mathrm{~kg} / \mathrm{Nm}^{3}$ to $\sim 11 \mathrm{~kg} / \mathrm{Nm}^{3}$, maintaining a $97 \%$ benzene capture.

- Steam could be lowered from $820 \mathrm{~g} / \mathrm{h}$ to $410 \mathrm{~g} / \mathrm{h}$, maintaining a $97 \%$ benzene capture. Thus, less steam is required in the stripper.

- The stripper temperature could be lowered from $160{ }^{\circ} \mathrm{C}$ to $130{ }^{\circ} \mathrm{C}$.

The new operating conditions of AREA-5 are based on these findings and are as follow: 
- Inlet gas flow: up to $5 \mathrm{Nm}^{3} / \mathrm{h}$.

- Absorber/stripper temperature: $35^{\circ} \mathrm{C} / 130^{\circ} \mathrm{C}$.

- Oil circulation: $50 \mathrm{~kg} / \mathrm{h}$.

- L/G: 11.

- $\quad$ Stripper steam: $2 \mathrm{~kg} / \mathrm{h}$.

AREA- 5 was tested with the full product gas generated in the MILENA gasifier with beechwood gasification operating at $850{ }^{\circ} \mathrm{C}$. Table 8 shows the benzene and toluene removal efficiency, where it can be seen that with the new AREA-5 (and new settings) the benzene removal is $97 \%$ and the toluene removal is above $99 \%$.

Table 8. Benzene and toluene removal efficiency in AREA-5 with beechwood gasification.

\begin{tabular}{ccccc}
\hline Feedstock & $\begin{array}{c}\text { Benzene PG } \\
\text { Vol\% db }\end{array}$ & $\begin{array}{c}\text { Benzene Removal } \\
\text { Efficiency (\%) }\end{array}$ & $\begin{array}{c}\text { Toluene PG } \\
\text { Vol\% db }\end{array}$ & $\begin{array}{c}\text { Toluene Removal } \\
\text { Efficiency (\%) }\end{array}$ \\
\hline Beechwood & 8000 & 97 & 1000 & $>99$ \\
\hline
\end{tabular}

The liquid BTX collected was also analyzed and the results are shown in Table 9. Here also the results obtained with AREA-1 are shown for comparison. It can be seen that the BTX composition collected with AREA-5 is similar to the BTX collected with AREA-1, which shows that the upscaled AREA with the new settings performs as expected.

Table 9. Composition of the collected BTX sample from beechwood gasification using AREA (wt $\%$ ).

\begin{tabular}{cccccc}
\hline Unit & Benzene & Toluene & $\begin{array}{c}\text { Xylenes and } \\
\text { Styrene }\end{array}$ & Ethylbenzene & Rest \\
\hline AREA-5 (beech) & 83 & 10 & 2 & 0 & 5 \\
AREA-1 (beech) & 86 & 9 & 2 & 0 & 3 \\
\hline
\end{tabular}

\section{Discussion}

BTX is an important chemical building block and if produced either from biomass gasification or mixed waste/RDF gasification it will replace (partially) fossil fuel-based BTX, hereby contributing to the bio-based and circular economy with clear environmental benefits for society. Moreover, this BTX co-production can improve gasification-based energy production business cases (biofuels, green gas, power and heat) considerably. An improvement of $30 \%$ in the revenues is reported for a scenario with co-production of BTX and SNG [6] and a return on investment of 5 to $7 \%$ points is reported as added value by co-production of BTX in waste-to-energy processes [7]. Besides, for the production of fuels, such as in the bio-SNG route, the presence of aromatics increases the coke formation over downstream catalytic beds and, in the power application, aromatics tend to slip through engines, increasing the emissions profile [5].

The removal of benzene and toluene from the product gas through condensation was not considered a viable option since it would require extremely low temperatures. For example, at a concentration of benzene of $1.2 \mathrm{vol} \%$ about $-50{ }^{\circ} \mathrm{C}$ would be required for a $90 \%$ removal efficiency. Therefore, an absorption process was selected, with an absorption oil that is in contact with the product gas in the absorber column, for the extraction of aromatics. This installation for the removal of BTX from the product gas is known as the Aromatics REmoval Apparatus (AREA).

In the present work, AREA was subjected to different qualities of product gas generated in the MILENA gasifier. There are many reviews elsewhere pointing out the influence of the different parameters in the gasification process, such as temperature, bed material, carrier gas and feedstock [22-26]. They show, for example, that an increase in temperature leads to more gas and less char and tars; that the use of steam favours the yield of $\mathrm{H}_{2}$; and that the use of bed materials, such as dolomite and olivine, lead to a reduction of tars. In the work presented here, each gasification experiment was performed with different 
goals and, as such, the operating conditions were different among the tests. However, regardless of the operating conditions, there are some qualities of the product gas that may be asserted to the feedstock used. It is seen that beechwood and lignin generate the largest amounts of $\mathrm{CO}$ and $\mathrm{CO}_{2}$ while the plastic waste generates the least amount. This is correlated to the presence of oxygen in the composition of the feedstock, which will then end up mostly in the form of $\mathrm{CO}$ and $\mathrm{CO}_{2}$ upon the gasification. Beechwood contains almost $49 \%$ oxygen while plastic waste contains about $13 \%$ oxygen. On the other side, the streams richer in plastic generate more lower hydrocarbons, such as $\mathrm{CH}_{4}$ and $\mathrm{C}_{2} \mathrm{H}_{4}$, and more benzene and toluene. About $10 \%$ of the original carbon ends up as benzene and toluene in the gasification of plastic waste, while this value is around $6 \%$ in the case of beechwood. However, regardless of the inlet gas tested, AREA always kept its high removal efficiencies. The direct removal of benzene and toluene from the product gas generated through gasification was successfully achieved, with a more than $97 \%$ benzene and more than $99 \%$ toluene removal efficiency.

Although the removal efficiencies are not affected, the quality of the collected BTX does change with the inlet product gas composition. If higher aromatics than benzene and toluene are present in the product gas then they will be extracted as well with AREA. It is seen that gasification of waste rich in plastic leads to a larger amount of aromatics being extracted, consequently leading to a reduction in the concentration of benzene and toluene present in the final liquid product. More than 90\% of the collected BTX from gasification of beechwood and lignin corresponds to benzene and toluene, while less than $80 \%$ is obtained upon the gasification of RDF or plastic waste. This will become crucial for the market implementation of the collected BTX, since the treatment that may be necessary will be dependent on the final liquid product composition. This should be the subject of future research.

It has been seen that the process conditions applied in AREA- 1 could be optimized without loss of removal efficiencies. The absorption oil used could be reduced up to three times and the steam halved while the benzene removal efficiencies remained above $97 \%$. These results were taken into account during the development of the new unit, AREA-5, upscaled to be able to process the full product gas generated in the MILENA gasifier. For the past work, a slip-stream of about $1 \mathrm{Nm}^{3} / \mathrm{h}$ of the MILENA gasifier was used and this was upgraded to the full gasifier capacity of $3-5 \mathrm{Nm}^{3} / \mathrm{h}$ product gas in AREA-5. One of the changes that was realized, due to the increased scale, was the plate-type heat exchangers that were installed for the oil circulation, to allow heat recovery between the hot and cold stream. The operating conditions chosen for the new unit are based on the findings with AREA-1, with a reduction of $L / G$ to 11 in the absorber and a reduction of steam to $2 \mathrm{~kg} / \mathrm{h}$ in the stripper.

AREA-5 was tested with the full product gas generated in the MILENA gasifier with beechwood gasification operating at $850{ }^{\circ} \mathrm{C}$. The benzene removal was of $97 \%$ and the toluene removal was above $99 \%$. The liquid BTX collected was also analyzed and the results are similar to the BTX collected with AREA-1, with more than $90 \%$ being benzene and toluene, which shows that the upscaled AREA with the new settings performs as expected.

\section{Conclusions}

BTX has been successfully extracted from the product gas generated from biomass and waste gasification with AREA. The removal efficiency is above $97 \%$ for benzene and above $99 \%$ for toluene. The technology was tested with different qualities of product gas generated from the gasification of several feedstocks, such as beechwood, lignin, sewage sludge, paper rejects, RDF and plastic waste. Regardless of the product gas, AREA always kept its high removal efficiencies. More than $90 \%$ of the collected BTX from the gasification of beechwood and lignin corresponds to benzene and toluene, while less than $80 \%$ is obtained upon the gasification of RDF or plastic waste. The technology was upscaled and optimized to the full capacity of the product gas generated in the gasifier, about $5 \mathrm{Nm}^{3} / \mathrm{h}$ dry gas, without a loss of efficiency. The operating conditions chosen for the new unit are 
based on the findings with the previous unit, with a reduction of L/G to 11 in the absorber and a reduction of steam to $2 \mathrm{~kg} / \mathrm{h}$ in the stripper. The collected BTX with the upscaled AREA is similar to the BTX collected with the previous unit, with more than $90 \%$ being benzene and toluene, which shows that the upscaled AREA with the new settings performs as expected.

\section{Patents}

The work on the BTX recovery from a diluted gasification gas proved to be an innovation, since the technology available in the market was developed for gases containing completely different gas compositions. There has been one patent filed that describes the innovation necessary to achieve this high removal efficiency with a dilute gas. The patent number is NL20172018906.

Author Contributions: C.M.V.: Conceptualization, methodology, investigation, data curation, writingoriginal draft preparation, writing-review and editing, project administration. E.B.: conceptualization, investigation, data curation, writing-original draft preparation, writing-review and editing. B.V.: validation, writing-original draft preparation, writing-review and editing, funding acquisition. All authors have read and agreed to the published version of the manuscript.

Funding: Several projects have funded this research. The Dutch Ministry of Economic affairs is acknowledged with the several grants: TEBE113008, TEBE115001, TEBE117010, TBBE218003, BBE1608, and via the TNO internal funds 2020 Bio SMO and 2021 Bio SMO. The scientific work was supported as well by the EU H2020 project AMBITION, Grant Agreement number 731263.

Institutional Review Board Statement: Not applicable.

Informed Consent Statement: Not applicable.

Data Availability Statement: The data is contained within the article.

Acknowledgments: The authors want to acknowledge the valuable work performed by Lex Bos and Dennis Slort in the design, development and operation of AREA.

Conflicts of Interest: The authors declare no conflict of interest. The funders had no role in the design of the study; in the collection, analyses, or interpretation of data; in the writing of the manuscript, or in the decision to publish the results.

\section{References}

1. Bilich, R.C. Climate Change and the Great Plague Pandemics of History: Causal Link between Global Climate Fluctuations and Yersinia Pestis Contagion? Master's Thesis, University of New Orleans, New Orleans, LA, USA, 15 December 2007.

2. Kaniewski, D.; Marriner, N. Conflicts and the spread of plagues in pre-industrial Europe. Humanit. Soc. Sci. Commun. 2020, 7, 162. [CrossRef]

3. Masson-Delmotte, V.; Zhai, P.; Pörtner, H.-O.; Roberts, D.; Skea, J.; Shukla, P.R.; Pirani, A.; Moufouma-Okia, W.; Péan, C.; Pidcock, R.; et al. IPCC, 2018: Global Warming of $1.5^{\circ} \mathrm{C}$. An IPCC Special Report on the impacts of global warming of $1.5^{\circ} \mathrm{C}$ above pre-industrial levels and related global greenhouse gas emission pathways, in the context of strengthening the global response to the threat of climate change, sustainable development, and efforts to eradicate poverty. in press.

4. de Jong, E.; Stichnothe, H.; Bell, G.; Jorgensen, H. Bio-Based Chemicals A 2020 Update; IEA Bioenergy: Petten, The Netherlands, 2020.

5. Rabou, L.P.L.M.; Aranda Almansa, G. 500 Hours Producing bio-SNG from MILENA Gasification Using the ESME System ECN System for MEthanation (ESME): A Novel Technology Successfully Proven; ECN-E-15-008; The Energy Research Centre of The Netherlands: Petten, The Netherlands, 2015.

6. Grootjes, A.J.; Vreugdenhil, B.J.; Aranda Almansa, G.; Kroon, P. Gasification of Plastics-Containing Residue Streams: Product Gas Composition and Economics of Biochemicals/Monomers Retrieval/Co-Production; TNO 2018 R11007; The Energy Research Centre of The Netherlands: Petten, The Netherlands, 2018.

7. Mourao Vilela, C.F.; Vreugdenhil, B.; Boymans, E.; Shijaz, H. Valorisation of the Green Gas route with Bio-BTX co-production. In Proceedings of the 28th European Biomass Conference \& Exhibition (EUBCE), Virtual, 6-9 July 2020.

8. Gruter, G.; Engelen, E. Overzicht Initiatieven Rond Bio-Aromaten; Platform Agro-Papier-Chemie: 's-Hertogenbosch, The Netherlands, 2014.

9. Ghorbannezhad, P.; Firouzabadi, M.D.; Ghasemian, A.; de Wild, P.J.; Heeres, H.J. Sugarcane bagasse ex-situ catalytic fast pyrolysis for the production of benzene, toluene and xylenes (BTX). J. Anal. Appl. Pyrolysis 2018, 131, 1-8. [CrossRef]

10. Sudolsky, D. Commercializing Renewable Aromatics for Biofuels, Biobased Chemicals and Plastics Chemical Recycling. Ind. Biotechnol. 2019, 15, 330-333. [CrossRef] 
11. Cioc, R.C.; Lutz, M.; Pidko, E.A.; Crockatt, M.; van der Waal, J.C.; Bruijnincx, P.C.A. Direct Diels-Alder reactions of furfural derivatives with maleimides. Green Chem. 2021, 23, 367-373. [CrossRef]

12. Liakakou, E.T.; Vreugdenhil, B.J.; Cerone, N.; Zimbardi, F.; Pinto, F.; André, R.; Marques, P.; Mata, R.; Girio, F. Gasification of lignin-rich residues for the production of biofuels via syngas fermentation: Comparison of gasification technologies. Fuel 2019, 251, 580-592. [CrossRef]

13. Grootjes, A.J. Reject gasifier ESKA. In IEA Bioenergy Task 33 Workshop on Waste Gasification; IEA Bioenergy: Petten, The Netherlands, 2018.

14. Grootjes, A.J.; Liakakou, E.T.; Boymans, E.H.; Zwart, R.W.R. Final Report TKI Toeslag Project Biomass to Biofuels (B2B); TNO 2019 R11419; TNO: Petten, The Netherlands, 2019.

15. Mourao Vilela, C.F. Gasification of end-of-life plastics. In IEA Bioenergy Task 33 Workshop on Waste Gasification; IEA Bioenergy: Birmingham, UK, 2019.

16. Van der Meijden, C.M. Development of the MILENA Technology for the Production of Bio-SNG. Ph.D. Thesis, Eindhoven University of Technology, Eindhoven, The Netherlands, 6 December 2010.

17. Boerrigter, H.; van Paasen, S.V.B.; Bergman, P.C.A.; Konemann, J.W.; Emmen, R.; Wijnands, A. OLGA Tar Removal Technology; ECN Report, ECN-C-05-009; ECN: Petten, The Netherlands, 2005.

18. Aranda Almansa, G.; Bos, A.; Rabou, L.P.L.M.; Vreugdenhil, B.J.; van der Waal, J.K.; van Zandvoort, I.; van Doorn, J. Green Birds Project Final Report; ECN-E-17-046; ECN: Petten, The Netherlands, 2017.

19. Aranda Almansa, G.; Bos, A.; Fryda, L.E.; van Zandvoort, I.; van der Waal, J.K.; van Klink, G.; van Doorn, J.; Lok, C.M. Blue Bird Final Report; ECN-E-18-027; ECN: Petten, The Netherlands, 2018.

20. Green, D.W.; Perry, R.H. Perry's Chemical Engineers Handbook, 8th ed.; The McGraw-Hill Companies, Inc.: New York, NY, USA, 1999; Chapter 14; 98p.

21. Colburn, A.P. The Simplified Calculation of Diffusional Processes: General Consideration of Two-Film Resistances. Trans. Am. Inst. Chem. Eng. 1939, 35, 211.

22. Sikarwar, V.S.; Zhao, M.; Clough, P.; Yao, J.; Zhong, X.; Memon, M.Z.; Shah, N.; Anthony, E.J.; Fennell, P.S. An overview of advances in biomass gasification. Energy Environ. Sci. 2016, 9, 2939-2977. [CrossRef]

23. Heidenreich, S.; Foscolo, P.U. New concepts in biomass gasification. Prog. Energy Combust. Sci. 2015, 46, 72-95. [CrossRef]

24. Devi, L.; Ptasinski, K.J.; Janssen, F.J.J.G. A review of the primary measures for tar elimination in biomass gasification processes. Biomass Bioenergy 2003, 24, 125-140. [CrossRef]

25. Ahmad, A.A.; Zawawi, N.A.; Kasim, F.H.; Inayat, A.; Khasri, A. Assessing the gasification performance of biomass: A review on biomass gasification process conditions, optimization and economic evaluation. Renew. Sustain. Energy Rev. 2016, 53, 1333-1347. [CrossRef]

26. Mourao Vilela, C.F. Primary Methods in Biomass Gasification for Gas Conditioning and Cleaning. Ph.D. Thesis, Eindhoven University of Technology, Eindhoven, The Netherlands, 5 November 2012. 